\title{
An accelerator worth fighting for
}

The Large Hadron Collider project faces new financial obstacles. Some proposed solutions to its problems are implausible. Others can surely be found, but will need great skill from CERN's management in limiting the damage to the laboratory.

WITH the best will in the world, people can commit themselves to an agreement only to find that circumstances change and that what looked like an unbeatably reasonable deal has turned into a millstone. Resolving the dilemma may amount to a battle between expedience and honour but, whatever one then does, somebody will be upset. That is where the member states of the European Laboratory for Particle Physics (CERN) will soon find themselves, following new pressure from some of them to curtail its costs even more than it has done already.

But what circumstances have changed since 1994, when the proposal to build CERN's next major accelerator, the Large Hadron Collider (LHC), was unanimously approved by its member-state governments? Certainly, the case for doing this \$2-billion piece of physics has not weakened. The means by which matter acquires mass remains a profound unknown. The best theoretical answer we have applies to obscure particles that carry one of the fundamental forces - the electroweak force. Their masses are thought to arise by the action of a hypothetical particle, the Higgs boson, of which there may be several varieties. Although there is plenty of other fundamental physics that the LHC is expected to tackle, its most important foreseeable role will be to explore 'the Higgs sector' of the standard model of high-energy physics.

In the absence of the United States' late Superconducting Super Collider project, the LHC will provide unique access to Higgs processes. CERN's 19 member countries in western and central Europe, and subsequently Russia, India, Canada, Japan and, almost certainly, the United States are willing to find the money over the next ten years or so to carry out such science. Rightly, that fundamental commitment remains strong.

What also has not changed is CERN's persistent and conspicuous success at achieving what its member states demand of it: currently, pursuing a diminishing budget by losing staff, closing facilities prematurely and trimming overheads. What is more, as part of its consideration of joining the LHC programme, the US Department of Energy issued in June a glowing assessment of CERN's performance, finding the LHC project to be functioning well, under a strong management team, and on track for possible completion in 2005.

Despite that, the formula by which member states' contributions are calculated has produced a drastic increase in the annual cost of membership to the United Kingdom, as a result of changes in relative economic performance and currency exchange rates. The United Kingdom is not alone in experiencing pressures on its domestic particle-physics programmes, although it is only now that other countries are beginning to make noises about the situation. Nevertheless, CERN would be justified in playing the injured innocent: ahead of the 1994 approval of the LHC, it presented all the costs up front - both of the accelerator and of its detectors, which are being funded predominantly from domestic programme budgets - and conditions of membership have not changed.

A critical new factor is the determination of Germany's government to adopt budgets aimed at meeting criteria established by the 1992 Maastricht Treaty, necessary to the establishment of a single European currency. The severe consequences for European science of that policy were revealed in our pages last week (Nature 382, 285; 1996). Perhaps it is a political inevitability that domestic science programmes should fare better than international collaborations, which attract few votes. That would be consistent with the success of Germany's national high-energy facility DESY in being awarded virtually level funding next year, in contrast to the 9.3 per cent cut likely for CERN.

Despite CERN's relatively blameless track record, the political pressures confronting its council could well prove irresistible. So what are the obstacles to possible ways forward, and are they as insurmountable as some claim? One option is to try to turn CERN into a truly international facility - to scrap its European identity, in other words. To hard-pressed member states, spreading the costs may sound like good sense.

One obstacle to that course is probably spurious. Despite references to its European role, the constitution of CERN does not explicitly prohibit non-European countries from becoming members. It would require a unanimous vote of member states to permit it, and Europhilia (or Anglo-Saxophobia) may be too strong in some for the possibility to be contemplated. But the genuine obstacle is that it is not in the interests of countries such as the United States or Japan to join CERN as members. Their highenergy physics communities are dominated by researchers whose interests lie in domestic facilities, such as KEK and SLAC. To join CERN commits members to paying establishment costs, including pensions. And even if their own finances were ideal, the US Congress and the Japanese Diet seem unlikely to favour a scheme that has never been canvassed before, and which would be a blatant attempt to get the Europeans out of a financial hole.

Given the political realities, another alternative may prove to be the only one: a revision of the LHC programme. Given CERN's overheads, slowing down construction of the accelerator can only increase its total cost, but may reduce annual costs to members. Changes in the deployment of the massive and expensive detectors may be possible, though at the risk of reducing the scientific value for money for the participants. If the priority for LHC physics remains sufficiently high, CERN may also be forced to think hitherto unthinkable thoughts about its other programmes, although managers will say that everything possible, draconian or otherwise, has already been done.

In considering these problems over the next few weeks and months, the governments of CERN's members states should keep in mind that maintaining the confidence of non-member states in Europe's capacity to deliver is vital. Meanwhile, European highenergy physicists - or at least those participating in the LHC and their institutions will need to keep all their lobbying wits about them.

But the real pressure will be on CERN's own management and scientists. They have a track-record, an intellectual authority and a public profile that stand them in good stead. Despite unfavourable winds from member states, they have no reason to give an inch yet. That is especially true given that there is no easy inch to give. But there will come a point later this year when member-state representatives and CERN's leaders will once again be at loggerheads over the finances. If the governments insist on 10 per cent cuts, the LHC project may collapse. If compromise is possible, the LHC's future will surely depend on the political astuteness of CERN's management and influential supporters. 